\title{
Building consensus on identifying research mentoring gaps and finding ways of addressing the gap in a Kenyan college of health sciences
}

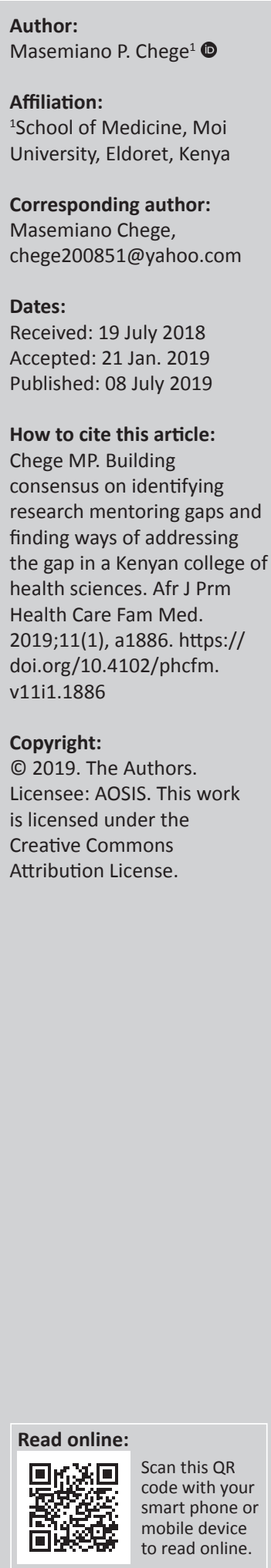

Background: The concept of mentoring in clinical practice has traditionally focused on moving graduates from novice to more respectable positions within the clinical practice hierarchy. With the growing emphasis on evidence-based practice, the role of research in generating evidence for practice cannot be overemphasised. Mentoring in clinical operational research for both students and junior members of academic staff in health professionals' training colleges is as important as mentoring for clinical skills.

Aim: This study aimed at building consensus on possible ways of enhancing research mentoring for graduate students and members of academic staff in a college of health sciences.

Setting: The study was conducted within Moi University College of Health Sciences (MUCHS) in Eldoret, Kenya.

Methods: The study population was composed of academic staff members and registered graduate students by the end of 2015. All academic staff and graduate students were eligible to participate. The Delphi technique was used to not only collect individual opinions but also build consensus. During the first iteration, questions were sent for which open-ended responses were needed. Responses from the first round were grouped into patterns and themes that guided the writing of questions for the subsequent rounds.

Results: The response rate was 78\%. There was consensus in appreciating that mentoring was fundamental for career growth in clinical practice and research and needed for improving and developing formal structure for effective mentoring. It was crucial to establish training programmes for mentors and for accrediting them.

Conclusion: Enhancing of current research mentoring in MUCHS was needed and expected by graduate students and academic staff.

Keywords: mentoring; research; Delphi technique; iterations; consensus; graduate students; academic members of staff.

\section{Background}

Available data on the role of mentoring in medical practice and research reporting it as beneficial at each stage of training and associating it with greater research productivity, career retention and promotion. Most of these data are from high-income countries. . $2,3,4,5,6,7,8,9$ Positive effects of wellstructured mentoring programmes in graduate programmes have been documented..$^{10,11}$

There is also evidence that early career mentoring for translational researchers is a process that aims at junior faculty members evolving from novice to expert researchers in a coordinated and monitored programme. This process has been most effective where experts and more experienced researchers apply tasks that are also common in other forms of human relationships. These include recognising compatibility between mentor and mentee, finding time for the needed activities, establishing patterns, agreeing on goals and ensuring that they are achieved..$^{4,7,12,13,14,15,16}$

In most African and other low- and middle-income countries, resource constraints remain a big barrier for developing effective clinical and research mentoring infrastructure. There are, however, positive data that demonstrate that collaboration, between African medical schools and those that are less resource-constrained, is working towards infrastructural and financial support for the development of mentoring programmes in these African medical schools. ${ }^{17,18,19}$ 
According to the World Development Index (WDI) data on health systems by the World Bank in 2015, in Kenya, the doctor to population ratio was at 0.2 per $1000 .{ }^{20}$ In Kenya, nearly all postgraduate medical school training courses have a stringent compulsory research training programme that requires the candidate to write a thesis, which would be determined by graduate studies' examiners, to obtain the postgraduate degree. The period of graduate training in Kenya offers a unique opportunity for research mentoring to nurture researchers in biomedical sciences.

The Moi University School of Medicine has an above average regional rating in research output within Eastern Africa. ${ }^{21}$ This is the result of a very fruitful partnership with the 'Academic Model Providing Access to Health Care (AMPATH) Consortium'. The Academic Model Providing Access to Health Care is an educational medical partnership between North American academic health centres led by the Indiana School of Medicine and the Moi University School of Medicine, and has flourished in the time since it started in 1989.22 This collaborative effort has benefited health service delivery at the regional level in western Kenya where AMPATH and the Moi University collaborate with the county health departments to enhance chronic disease management within level three and four public health facilities. In the Moi University School of Medicine Teaching Hospital, the collaboration in clinical teaching, service and research has resulted in highly rated medical graduates. In research, the collaboration focuses significantly in translational research where research experts from partner universities in the west mentor Kenyans to grow from novices to expert researchers.

A pilot survey that interviewed graduate students, and junior and senior faculty members revealed that there was a significant satisfaction gap in research mentoring that needed to be addressed. It was agreed that the best approach to identifying and addressing the gap would be through consensus building and that the Delphi technique would be most appropriate for identifying and addressing the existing research mentoring gap in the Moi University College of Health Sciences (MUCHS).

\section{Broad objective}

The aim of this study was to identify the research mentoring gap and find ways of addressing it for graduate students and faculty members in the MUCHS.

\section{Specific objectives}

- To identify the research mentoring gap among graduate students and junior faculty members in MUCHS.

- To build consensus on ways to enhance research mentoring among graduate students and faculty members in MUCHS.

- To use evidence-based best practices through consensus to propose cost-effective methods to enhance research mentoring in MUCHS.

\section{Methods Design}

We used the Delphi technique, which is a qualitative study design that facilitates a group communicator process that aims to achieve convergence of opinions on a specific real-world issue. This technique can use mixed qualitative and quantitative methods. During a feasibility survey, it was observed that some potential participants significantly controlled opinion during group discussions, when conducting in-depth interviews on faculty colleagues and it was realised that there was a possibility of compliance bias in the responses. The Delphi technique suited this study because there was no direct interaction among the respondents or even with the interviewers.

\section{Site}

The study setting was MUCHS, Eldoret, Kenya.

\section{Study population}

The study population comprised senior faculty members, junior faculty members and graduate students from MUCHS.

\section{Inclusion criteria}

- Academic members of staff from different departments and schools on the December 2015 payroll in the MUCHS.

- Graduate students on the graduate students' roll for the different departments and schools on the MUCHS in December 2015.

\section{Exclusion criteria}

- Visiting academic staff from other universities at the time of the study.

- Academic members of staff and graduate students who declined to participate.

\section{Sampling procedures}

The following three categories of participant included:

- Senior faculty members: senior lecturers, associate professors and professors

- Junior faculty members: lecturers and tutorial fellows

- Graduate students on the graduate students' roll for the different departments and schools on the MUCHS in December 2015.

The three categories of graduate research work (senior faculty members, junior faculty members and graduate students) were conveniently selected to participate. This was guided by a survey carried out before the study when it was observed that all stakeholders (experts and learners) of research had differing opinions on ways to enhance research mentoring. 
All senior members (senior lecturers, associate professors and professors) and junior academic staff from the different departments and schools were eligible to participate. A total of 460 participants (55 senior academic staff, 160 junior academic staff and 245 graduate students) were eligible to participate in the study.

\section{Data collection methods}

Potential participants expressed support for the use of the email, with a Word document attachment, for receiving and sending responses.

For the first iteration, an open-ended question was mailed as a Word attachment to the eligible participants. The question read: 'In your own opinion and observation, what does the Moi University College of Health Sciences (schools and departments) need to do to enhance research mentoring for faculty and graduate students?'

The responses of the first iteration would be grouped into themes within the three separate categories of participants and only those responses that had more than 50\% concordance, among participants, would be used for the second iteration.

For the second and third iterations, consensus was set at an agreement of $80 \%$ and above. This was to minimise ambiguity.

For the third iteration, the same questions were sent out again to the same participants with highlights on themes that lacked consensus during the second iteration.

Regular reminders (by email, short mail messages by phone) were sent out every fortnight to participants who delayed responses during the first iteration, and those who did not respond after three reminders were declared as not consenting and lacking interest to participate in the first round.

The responses to the second and third iterations were prompt with minimal need for sending reminders.

\section{Data management}

The responses to the first iteration question were analysed using pattern matching to develop themes that were used to prepare questions for the second and third iterations.

The responses to the questions of the second and third iteration questions were analysed as quantitative data and results presented in percentages.

Signed informed consent for all participants was a precondition to participation for the first iteration.

\section{Study implications}

Building of consensus among research experts and teachers, junior faculty members and graduate students on cost-effective ways for research mentoring in MUCHS will influence policy and practice in MUCHS and other similar institutions.

\section{Study limitations}

Our study aimed at interviewing all participants and so we did not have a scientifically representative sample. Without scientific sampling, it is possible that those who declined to participate may have a differing opinion, but with an above $75 \%$ response rate, the majority opinion can be considered as generally representative.

\section{Ethical considerations}

Ethical approval was obtained from the Moi University Institutional Research Ethics Committee (IREC) and permission to conduct the study was obtained from the Principal of the Moi University College of Health Sciences (Formal approval number: FAN: IREC 1488).

\section{Results}

The first iteration question was sent out to 55 senior faculty members, 160 junior faculty members and 245 postgraduate students.

Those who consented to participate and send responses back were $356(45,123$ and 188) for senior, junior faculty members and graduate students, respectively. This was a response rate of $82 \%, 77 \%$ and $77 \%$ for the three categories of participants.

The responses from the three categories of participants to the open-ended questions of the first iteration are summarised in Tables 1-3.

Only responses that had above $50 \%$ consensus were included in developing the themes that guided the second and third iterations. This was done to minimise inclusion of equivocal responses.

For Tables 1-3, the following apply:

- The different rows present collated themes of responses collected

- Different columns represent collated themes of responses about what may be needed to enhance research mentoring for the specific group

- Tables 1-3 represent collated themes of responses on what each group proposed should happen to enhance mentoring for each of the stakeholders.

These responses were then merged along common themes and used to develop closed questions for the second and third iterations. The summary of these responses is summarised in Tables 4 and 5.

\section{The three items were presented as a summary of the responses in the second round for the third round (iteration)}

By the end of the third iteration, we had realised the consensus from the participants. 
TABLE 1: Summary of first iteration responses by senior faculty members.

\section{Senior faculty expectation of graduate students}

- All should understand that mentoring is fundamental for career growth, promotion and retention in clinical practice and research

- Students should write project proposals in line with research interests of the faculty to enhance effective supervision and increase chances of publication

- A forum in the schools should be created where teacher present research 'grey' areas with high research impact to graduate students

Students should also be encouraged to present on their areas of research interest during the same forum

- Introduction of formal mentorship unlike the current emphasis on research supervision

- Students to choose own mentors and supervisors

- Students to be mentored by working within projects of

the mentors as opposed to students doing their own

project or thesis

- Relevant journals to be made available in departments

- Improvement of infrastructure and study facilities

- Logistic support to attend and participate in scientific conferences and other open forums

\section{- Proactive assigning of mentors and mentees}

- Faculty training on mentorship

- Protected time for mentoring interaction

- Graduate students to be involved in research projects by senior faculty and use them for their dissertation. PI as mentors with relationships continue after graduation

- Need for a conducive environment for research

- Research infrastructural enhancement

(equipment and tools)

- Need to 'infuse' graduate students with research appreciation and its needs

Moi University to fund MMed, MSc and PhD research as part of tuition

- Regular meetings between teachers and learners (at least Regular meetings
once a month)

- Relationship between student and teacher to be guided Relationship between student and teacher to be guided
by focus on student benefit and on 'equal' terms or levels by focus on student benefit and on 'equal' terms or levels - Need to address

the mentors [sic]
Collaboration and networking among departments and

their students

- Research skills foundation should be laid down well for beginners to equip them with the needed research skills and minimise the time taken to develop a research proposal

- The institution should have proper time guidelines for research, for example, for promotion from first to second research, for example, for promotion from first to second year, all research proposals should be presented at the same time such as within a calendar week with wide
audience (students, faculty and other research experts)

- Enhance mentorship development for the above to succeed

- Having a good or large pool of academic staff who participate actively in research

- Organised research seminars held at least quarterly within MUCHS

- Collaborative research involving researchers from partners across the oceans

- Students to choose their supervisors and mentors.

Departments to protect popular mentors from overload

- Easy access to journal articles

- Journal clubs participation where journal articles are reviewed and critiqued

- Monthly meetings with faculty to discuss progress on research and identify and resolve any difficulties

- Attend workshops on research and make presentations, scientific conferences

- Departmental libraries with basic research books, statistics books and other necessary resources - Graduate students' study rooms within departments - Reliable internet connection

Increase the number of graduate faculty to make them more available

- Have a fixed period and time on the timetable for research

- Increase the research courses and have these courses offered more than once (September-December) on admission. Could be taught several times during the $\mathrm{MSc} / \mathrm{MMed} / \mathrm{PhD}$ programme

- Develop a research fund for graduate students

\section{Expectations of senior faculty on junior faculty}

- All should understand that mentoring is fundamental for career growth, promotion and retention in clinical practice and research

- Actively apply for research grants and seek guidance from the seniors

- Junior faculty should be encouraged to present thei research interests within their departments for guidance

- research interests within their departments for guidance independent research interests should be encouraged to attend refresher courses (even with graduate students) or be guided by seniors within the department

- Seniors to mentor juniors

- Frequent workshops on mentorship

- Promotion points on effective mentoring

- More PhD and clinical fellowship programmes should be developed in the college as venues for mentoring

- Logistic support to attend and participate in scientific conferences and other open forums within and outside Kenya

- Training on mentorship

- Assigning mentors to junior faculty upon employment

- Set aside small grants for the faculty members to help in

mentoring

- Enhance collaboration for mentoring

- Need for creation of a research environment that nurtures research culture

- Need for infrastructural enhancement (equipment and other resources)

- Need for enhanced and structured research funding

- Create collaborative linkages between universities and research institutions

Encourage deserving researches with awards and other recognition

- Need for continuous mentoring to build skills in research

- Departmental and school and college workshops to

brainstorm on research ideas and areas of interest

- Staff motivation by the college needs to be enhanc

- Formal training on mentoring to be introduced

Need to identify new or novel questions within
departments that may raise departments to global recognition

- Members who have few research publications and research experience should be partnered with thos with more

- Departments to hire persons who do little other than research and use them as mentors for junior faculty

- Regular workshops to be started where faculty present their research activities. The workshops to include faculty and students

- Collaborative research among institutions

- Capacity building in research and research mentoring

- Journal clubs participation where journal articles are reviewed and critiqued

- Schools should develop guidelines on scientific research proposal development

- Departments should allocate specific time for research presentations

- Invitation of resource persons to talk on research within schools and departments

- Include students in research projects

- A common research office in the school. The office should be equipped with a computer, scanner and printer for ease of interaction between faculty and graduate students

- The school to organise regular refresher courses on the supervision of research

- Moi University to provide funding to facilitate research

- Members of departments to jointly write grants for

research funding. This would increase chances of success

- Include graduate students in faculty research activities

\section{Both junior and senior faculty}

- All should understand that mentoring is

fundamental for career growth, promotion and retention in clinical practice and research

- The mentor and mentee relationship should be close and mutually acceptable at every step

- The need for a forum within the college where - The nior faculty present their work and all attend (senior and junior faculty and graduate students)

- Allow change of supervisor anytime the student or supervisor is uncomfortable in continuing the relationship. No negative consequences

- Allow interests to guide mentor and mentee with the choice of who to work with

- Encourage more research exchange programmes - Recognition and merit awards on good mentormentee relationships

- Avail research grants

- Linkages and collaboration in teaching, research and learning

- Encourage a research culture with schools and departments

- Training on mentoring

- Continuous feedback on mentoring progress

Building relationships that enable a conducive mentoring environment

As above

As above

As above

- Protected time for mentors and mentees to interact needed

Formal research teams within departments and schools and colleges

- Graduate students and their mentors to be allocated time during which they present their work to other staff and faculty

- The departments and schools and colleges to reward and appreciate students and faculty members that do well

- Mutual respect for mentor and mentee

Observe timelines for submission of work and stick to them

- Each party to diligently do their part

- A common research department and library within the school and college

- A common research office in the school. The office should be equipped with a computer, scanner and printer for ease of interaction between faculty and graduate students

- Regular joint research seminars to share new ideas and progress on ongoing research or studies

MUCHS, Moi University College of Health Sciences; PI, principal investigator. 
TABLE 2: Summary of first iteration responses by junior faculty members.

\section{Junior faculty expectations of graduate students}

- The learners should be involved in choosing their research mentors unlike the current state where they supervisors are assigned to them

- Assigned projected time for mentoring interaction with students

- Students should actively seek and express interest in getting involved in

research projects that individual faculty members are involved in

- All should understand that mentoring is fundamental for career growth,

promotion and retention in clinical practice and research

- Research should be a guided process where the supervisor and the graduate student have a friendly learning environment that is non-threatening with the supervisor offering professional guidance while allowing the registrar to bring out his or her thoughts. The mentor should offer support during challenging times, for example, offer feasible suggestions on addressing difficult reviewer comments. The mentor should make comments. The mentor should make available any possible research grants to the mentee or advise when the research topic can attract research funds. The
supervisor should be accessible during the research period and get constant supervisor should be accessible
briefs on the research process

- At the completion of the research process with data and results analysed, the supervisor and mentor should maintain professional contact and be in constant communication on research matters and any other relevant professional assistance more so on the processes involved in publishing results of the study

- Departments should at least have a research agenda where graduate students can engage and participate in research with their mentors. Departmental research is one way the graduate students can observe their mentors actively engaged in research and learn from their mentors how they manage challenges encountered during the research process

\section{Junior faculty expectations of senior faculty}

- All should understand that mentoring is fundamental for career growth, promotion and retention in clinical practice and research

- The need for formal and structured training on mentoring

- Assigning mentors to junior faculty members as soon as recruited into schools and departments - Set aside small grants for faculty members to help with mentoring skills

- Enhance collaborations to purposefully target mentoring of faculty members

- The research capacity of faculty members should be enhanced through workshops like 'grant writing' workshops. It would be a good thing to have ongoing research either departmental or collaborative research with other universities where new or junior faculty members with very where new or junior faculty members with very little research experience can be incorporated and mentored by their senior colleagues. This is important because the research world is not a walk in the park; indeed, the research road is riddled with numerous challenges. Attracting research grants as a novice is not an easy task either and you have to belong to a 'members club'. Overcoming some of these challenges requires a helping hand. These helping hands are senior faculty members with research experience. Research mentorship programmes within the faculty may go a long way in fostering this

\section{Both junior and senior faculty}

- All should understand that mentoring is fundamental for caree growth, promotion and retention in clinical practice and research

- Explicitly adopt a research culture in departments and schools

- Training on mentor and mentee relationship

- Continuous and structured two-way feedback on mentoring progress

- Building relationships that enable a conducive mentoring environment

- Build research capacity for faculty and graduate students

- Actively run research mentorship programmes within departments

- Avail research grants and funds at coll research grants and funds at college level even if possible at the departmental level incorporating research funds in the departmental
budgets

- Support publishing frameworks, for example, reviewers network an publishing journal networks

TABLE 3: Summary of first iteration responses by graduate students.

\section{Graduate students expectations of fellow graduate Graduate students expectations of faculty} students

- Have a refined research question that can easily be answered by the set objectives

- Allocate adequate time for research-related activities

- Keep or follow research-related timeline

- Consult with supervisors more frequently

- An earlier communication on the need to conduct research as a student

- Make students aware of the need to self-sponsor themselves during research

- Steps to undergo before finally conducting the research
- Offer guidance on research question(s)

- Offer more guidance on the research proposal with more attention to the research methodology

- Involve graduate students in faculty research as a means of mentoring

- Provide prior information on the need to mentor students through research

- With earlier communicated areas of interest, the faculty members should be allocated students under their areas of specialisation or interest

- To have a clearly stipulated time schedule of when to meet

deadlines as pertains to student efforts

- To pair up faculty members with the same interest and ideas to create feasibility on the student side in terms of a common mind and expectation

- To be allowed to declare their availability for the students during the entire period of mentorship

TABLE 4: Summary of responses in the second iteration. Ways to enhance research mentoring

Graduate students expectations of faculty and students

$$
\text { - Team work }
$$

- To allow students and faculty members to meet and agree on the required terms of working

- Disclose to both on source of funding for the research work

- Clearly stipulate the role and expectations from each

Mentoring is fundamental for career growth, promotion and retention in clinical practice and research and must be embraced by all

Graduate students to be involved in faculty grants and other research projects. This will be an opportunity for a long-term mentor and mentee relationship

The need for a forum (at school and college level) where research ideas or topics of interest and uncovered areas are shared across the departments and schools

Formal training in mentoring for faculty and graduate students (graduate students play a part in choosing their mentors)

Points to be awarded for effective mentoring and points to be awarded for promotion of facultyi Formal introduction and declaration of research mentorship as opposed to the current research supervisor arrangement $\dagger$

The need to develop infrastructure that favours research (more space for student to interact among themselves and faculty members) within departments

Facilitate students and faculty members to attend and present in scientific conferences (local and international) Promote interest in reading research materials by providing relevant journals within departments Departments to employ persons who do mostly research (and little else) and use them as research mentorst

Recruit more graduate faculty members to make them more available to mentor and teach research and avail blocked time for research training and implementation for graduate students and faculty

Enhance collaborations with other universities that promote mentoring teaching or learning and research

The need for training on research supervision

\begin{tabular}{|c|c|c|c|}
\hline \multicolumn{2}{|c|}{ MUCHS (should do) } & \multicolumn{2}{|c|}{ MUCHS (should not do) } \\
\hline Frequency & $\%$ & Frequency & $\%$ \\
\hline 356 & 100.0 & 0 & - \\
\hline 356 & 100.0 & 0 & - \\
\hline 356 & 100.0 & 0 & - \\
\hline 320 & 90.0 & 36 & 10.0 \\
\hline 256 & 72.0 & 100 & 28.0 \\
\hline 219 & 61.5 & 137 & 38.5 \\
\hline 356 & 100.0 & 0 & - \\
\hline 356 & 100.0 & 0 & - \\
\hline 292 & 82.0 & 64 & 18.0 \\
\hline 128 & 36.0 & 228 & 64.0 \\
\hline 356 & 100.0 & 0 & - \\
\hline 356 & 100.0 & 0 & - \\
\hline 356 & 100.0 & 0 & - \\
\hline
\end{tabular}

MUCHS, Moi University College of Health Sciences.

$\uparrow$, Consensus threshold of $80 \%$ not achieved. 


\begin{tabular}{|c|c|c|c|c|}
\hline \multirow[t]{3}{*}{ Ways to enhance research mentoring } & \multicolumn{4}{|c|}{ What Moi University College of Health Sciences should do or not do } \\
\hline & \multicolumn{2}{|c|}{ MUCHS (should do) } & \multicolumn{2}{|c|}{ MUCHS (Should not do) } \\
\hline & Frequency & $\%$ & Frequency & $\%$ \\
\hline $\begin{array}{l}\text { 1. Mentoring is fundamental for career growth, promotion and retention in clinical practice and research } \\
\text { and must be embraced by all }\end{array}$ & 356 & 100.0 & 0 & - \\
\hline $\begin{array}{l}\text { 2. The need for formal structures for effective mentoring } \\
\text { - Initiate formal mentor(s) and mentee(s) programmes for graduate students and junior faculty members } \\
\text { - Establish modes of recognising and rewarding effective mentoring } \\
\text { - Establish formal local and international mentee and mentor exchange programmes }\end{array}$ & 356 & 100.0 & 0 & - \\
\hline $\begin{array}{l}\text { 3. The need for formal accredited training for mentors with categorisation based on an achievement } \\
\text { performance record }\end{array}$ & 356 & 100.0 & 0 & - \\
\hline
\end{tabular}

performance record

MUCHS, Moi University College of Health Sciences.

\section{Discussion}

Consensus by participants drawn from the graduate students, junior and senior faculty members of the MUCHS in Western Kenya was remarkable. By the end of the third iteration, the potential benefactors (senior faculty members) and beneficiaries (graduate students and junior faculty members) had unanimously agreed on ways needed to enhance research mentoring in this college that is located in a sub-Saharan African country.

By the third iteration the participants involved concurred that mentoring in research was requisite for career growth, promotion and retention in clinical practice and research. This crucial observation has been documented in studies that looked into mentoring in research and clinical practice. Most of the data are from developed countires. ${ }^{1,3,4,5,6,7,8}$

The important role played by mentoring in faculty development was supported by all junior faculty members, senior faculty members and graduate students and proposed as one that needed enhancing and structuring. There are available data that also support mentoring as crucial in faculty development. ${ }^{6,23,24,25,26}$ Decastro proposes a focus on developing a network of mentors geared towards individual needs of mentees instead of a theoretically assumed hierarchy of needs. This was also ranked high in our study. ${ }^{23}$

The participants in our study acknowledged that the current general assumption is that mentoring was going on in the MUCHS. There, however, was consensus on the need for structured mentoring that suited both the mentors and the mentees. Sambuco presented it more explicitly as '[an] Academic medical faculty often lacks the skills and knowledge necessary for successful negotiation, especially early in their careers, for effective mentoring to take place'.$^{27}$ There are also other available data that also emphasised the need for structured mentoring programmes. . $11,28,29^{2}$

Mentoring like any other academic engagement requires formal training and preparation of the mentors. The assumption that the successful careers of men and women make them effective mentors for those who look up to them for guidance has not worked to the satisfaction of the mentor and the mentee. One of the causes attributed to the poor results is the lack of well-trained and well-supported mentors. Abedin et al. proposed the need for validation and development of competencies for mentors. ${ }^{16,30,31,32}$
Our study participants proposed mentoring programmes that involved mentoring retreats, a mentoring consultation online (that included Kenyan and foreign experts). The same was presented by Fieldman et al. among other available documents on the subject. ${ }^{16}$

\section{Conclusion}

Our study findings on methods that would enhance research mentoring concurred with findings documented in developed countries. Although MUCHS encourages mentoring as part of training and faculty development, there was a need for formal structuring of mentoring programmes and finding ways to appreciate successful mentor and mentee programmes.

\section{Acknowledgements}

The author would like to thank the following people for their support in conducting this research: Vanderbilt-EmoryCornell-Duke (VECD) Global Health Fellows Consortium for awarding the Fogarty Clyaton-Deonder Mentoring Fellowship award for 2015; and those who played a part in the acquisition of the mentoring fellowship and guided the study process (specifically Prof. Paul O. Ayuo, Prof. Wendy P. O'Meara [Visiting Epidemiology professor from Duke University], Prof. Samuel Ayaya and Dr Andrew O. Obala - all of Moi University College of Health Sciences); Prof. Fabian Esamai, Principal, College of Health Sciences, for granting permission to the author to conduct the study; the AMPATH Consortium for facilitating and managing the fellowship grant; and, finally, the participants of the study for their open and very objective input.

\section{Competing interests}

The author declares that he has no financial or personal relationships that may have inappropriately influenced him in writing this article.

\section{Authors' contributions}

M.P.C. was the sole author of this article and involved in all parts of the research and the writing of the manuscript.

\section{Funding information}

Funding for this study was provided through a scholarship by Fogarty VECD Mentoring Fellow of the National Institute of Health, United States. 


\section{Data availability statement}

Data sharing is not applicable to this article as no new data were created or analysed in this study.

\section{Disclaimer}

The views and opinions expressed in this article are those of the author(s) and do not necessarily reflect the official policy or position of any affiliated agency of the authors.

\section{References}

1. Crockett ET. A research education program model to prepare a highly qualified workforce in biomedical and health-related research and increase diversity. BMC Med Educ. 2014;14:202. https://doi.org/10.1186/1472-6920-14-202

2. Dzirasa K, Krishnan RR, Williams RS. Incubating the research independence of a medical scientist training program graduate: A case study. Acad Med. 2015;90(2):176-179. https://doi.org/10.1097/ACM.0000000000000568

3. Eisen S, Sukhan S, Brightwell A, Stoneham S, Lond A. Peer mentoring: Evaluation of a novel program in Paediatrics. Arch Dis Child. 2014;99:142-146. https://doi. org/10.1136/archdischild-2013-304277

4. Keller HH, McCullough J, Davidson B, et al. The integrated nutrition pathway for acute care (INPAC): Building consensus with a modified Delphi. Nutr J. 2015;14(1):63. https://doi.org/10.1186/s12937-015-0051-y

5. Morrison-Beedy D, Aronowitz T, Dyne J, Mkandawire L. Mentoring students and faculty in faculty research: A win-win scenario. J Prof Nurs. 2001;17(6):291-296. https://doi.org/10.1053/jpnu.2001.28184

6. Ng E, Wang X, Keow J, Yoon JY. Fostering mentoring for clinician-investigator trainees: Overview and recommendations. Clin Inves Med. 2015;38(1):E1-E10. https://doi.org/10.25011/cim.v38i1.22408

7. Sakushima K, Mishina H, Fukuhara S, Sada K, Koizumi J, Sugioka T. Mentoring the next generation of physician-scientists in Japan: A cross-sectional survey of mentees in six academic medical centers. BMC Med Educ. 2015;15:54. https:// doi.org/10.1186/s12909-015-0333-2

8. Stamm M, Budderg-Fischer B. The impact of mentoring during postgraduate training on doctors' career success. Med Educ. 2011;45(5):488-496. https://doi. org/10.1111/j.1365-2923.2010.03857.x

9. Steiner JF. Promoting mentorship in transitional research: Should we hope for athena or train mentor? Acad Med. 2014;89(5):702-704. https://doi.org/10.1097/ ACM.0000000000000205

10. Donovan A, Donovan J. Mentoring in postgraduate training programmes: Views of Canadian programme directors. Med Educ. 2009;43(2):155-158. https://doi. org/10.1111/j.1365-2923.2008.03258.x

11. Young RA, DeHaven MJ, Passmore C, Baumer JG, Smith KV. Research funding and mentoring in family medicine residencies. Fam Med. 2007;39(6):410-418.

12. Pfund $C$, House $S$, Asquith $P$, et al. Training mentors of clinical and translational research scholars: A randomized control trial. Acad Med. 2014;89(5):774-782. https://doi.org/10.1097/ACM.0000000000000218

13. Sorkness CA, Pfund C, Asquith P, Drezner MK. Research mentor training: Initiative of the University of Wisconsin Institute for Clinical Translational Research. Clin TransI Sci. 2013;6(4):256-258. https://doi.org/10.1111/cts.12085
14. Pfund $C$, House $S$, Spencer $K$, et al. Research mentor training curriculum for clinical and translational researchers. Clin Transl Sci. 2013:6(1):26-33. https://doi. org/10.111/cts.12009

15. Lord JA, Mourtzanos E, McLaren K, Murray SB, Kimmel RJ, Cowley DS. A peer mentoring group for junior educators: Four years' experience. Acad Med. 2012;87(3):378-383. https://doi.org/10.1097/ACM.ob013e3182441615

16. Feldman MD, Haung L, Guglielmo J, et al. Training the next generation of research mentors: The University of California, San Francisco, Clinical \& Translational Science Institute Mentor Development Program. Clin TransI Sci. 2009;2(3):216-221. https://doi.org/10.1111/j.1752-8062.2009.00120.x

17. Made WK, Sanders D, Lehmann U. Building capacity to develop an African teaching platform on health workforce development: A collaborative initiative of universities from for sub Saharan countries. Hum Resour Health. 2014;12:31. https://doi.org/10.1186/1478-4491-12-31

18. Lalloo UG, Bobat RA, Pillay S, Wassenaar D. A strategy for developing future academic leaders for South Africa in a resource-constrained environment. Acad Med. 2014;89(8 suppl):S55-S59. https://doi.org/10.1097/ACM.0000000000000354

19. Matovu JKB, Wanyenze RK, Mawemuko S, et al. Building capacity for HIV/AIDS program leadership and management through mentored Fellowships. Globa Health Action. 2011;4:5815. https://doi.org/10.3402/gha.v4i0.5815.

20. World Development Index (WDI). Data on health systems by the World Bank in 2015 [homepage on the Internet]. Washington, DC: World Bank; 2015 [cited 2018 Mar 15]. Available from: http://wdi.worldbank.org/table 2.15.

21. Webometrics (Ranking Web of Universities) [homepage on the Internet]. [cited 2018 Mar 15]. Available from: http://www.webometrics.info/en/africa/kenya $\% 20$

22. The academic model providing access to healthcare - AMPATH [homepage on the Internet]. n.d. [cited 2018 Jun 8]. Available from: http://www.ampathkenya.org/.

23. DeCastro R, Griffith KA, Ubel PA, Steward A, Jagshi R. Mentoring and the career satisfaction of male and female academic faculty. Acad Med. 2014;89(2):301-311. https://doi.org/10.1097/ACM.0000000000000109

24. Steiner JF, Lanphear BP, Curtis $\mathrm{P}, \mathrm{Vu}$ KO. Indicators of early research productivity among primary care fellows. J Gen Intern Med. 2002;17(11):845-851. https://doi. org/10.1046/j.1525-1497.2002.10515.x

25. Steiner JF, Curtis $P$, Lanphear BP, Vu KO, Main DS. Assessing the role of influential mentors in the research development of primary care fellows. Acad Med. 2004;79(9):865-872. https://doi.org/10.1097/00001888-200409000-00012

26. Wasserstein AG, Quistberg DA, Shea JA. Mentoring at the University of Pennsylvania: Results of faculty survey. Soc Gen Intern Med. 2007;22:210-214. https://doi.org/10.1007/s11606-006-0051-x

27. Sambuco D, Dabrowska A, Decastro R, Stewart A, Ubel PA, Jagsi R. Negotiation in academic medicine: Narratives of faculty researchers and their mentors. Acad Med. 2013;88(4):505-511. https://doi.org/10.1097/ACM.0b013e318286072b

28. Chapman A, Guay-Woodford LM. Nurturing passion in a time of academic climate change: The modern-day challenge of junior faculty development. Clin J Am Soc Nephrol. 2008;3:1878-1883. https://doi.org/10.2215/CJN.04240808

29. Johnson KS, Hastings SN, Purser JL, Whitson HE. The junior faculty laboratory: An innovative model of peer mentoring. Acad Med. 2011;86(12):1577-1582. https:// doi.org/10.1097/ACM.0b013e31823595e8

30. Abedin Z, Biskup E, Silet MA, et al. Deriving Competencies for mentors of clinical and translational scholars. Clin. And Transl Sci J. 2012;5(3):273-208. https://doi. org/10.1111/j.1752-8062.2011.00366.x

31. Johnson MO, Suback LL, Brown JS, Lee KA, Feldman MD. An innovative to train health sciences researchers to be effective clinical and translational - Researcher mentors. Acad Med. 2010;85(3):484-489. https://doi.org/10.1097/ACM.0b013e $3181 \mathrm{cccd} 12$

32. Moskowitz J, Thompson JN. Enhancing the clinical research pipeline: Training approaches for a new century. Acad Med. 2001;76(4):307-315. https://doi. org/10.1097/00001888-200104000-00004 